\title{
Expression of NDRG2 is down-regulated in high-risk adenomas and colorectal carcinoma
}

\author{
Anders Lorentzen ${ }^{1}$, Lotte K Vogel2 ${ }^{2}$, Rikke H Lewinsky1, Mona Sæbø ${ }^{3}$, \\ Camilla F Skjelbred ${ }^{3,4}$, Sine Godiksen², Geir Hoff ${ }^{5}$, Kjell M Tveit ${ }^{7}$, Inger Marie \\ Bowitz Lothe $^{6}$, Tone Ikdahl7, Elin H Kure ${ }^{3,6,7}$ and Cathy Mitchelmore*1
}

\begin{abstract}
Address: ${ }^{1}$ Eucaryotic Cell Biology Research Group, Department of Science, Roskilde University, Roskilde, Denmark, ${ }^{2}$ Department of Cellular and Molecular Medicine, University of Copenhagen, Blegdamsvej 3, Denmark, ${ }^{3}$ Telemark University College, Faculty of Arts and Sciences, Bø i Telemark, Norway, ${ }^{4}$ Department of Laboratory Medicine, Section of Medical Genetics, Telemark Hospital, Skien, Norway, ${ }^{5}$ Department of Medicine, Telemark Hospital, Skien, Norway, ${ }^{6}$ Department of Pathology, Ullevaal University Hospital, 0407 Oslo, Norway and ${ }^{7}$ The Cancer Center, Ullevaal University Hospital, 0407 Oslo, Norway

Email: Anders Lorentzen - anbl@ruc.dk; Lotte K Vogel - vogel@imbg.ku.dk; Rikke H Lewinsky - lewinsky@ruc.dk; Mona Sæbø - mona.sabo@hit.no; Camilla F Skjelbred - camilla-furu.skjelbred@sthf.no; Sine Godiksen - sinego@imbg.ku.dk; Geir Hoff - geir.hoff@sthf.no; Kjell M Tveit - kjell.tveit@uus.no; Inger Marie Bowitz Lothe - ingermariebowitzlothe@ulleval.no; Tone Ikdahl - tone.ikdahl@uus.no; Elin H Kure - elur@uus.no; Cathy Mitchelmore* - mitch@ruc.dk

* Corresponding author
\end{abstract}

Published: 12 October 2007

BMC Cancer 2007, 7:192 doi:10.1186/147|-2407-7-192
Received: 18 June 2007

Accepted: 12 October 2007

This article is available from: http://www.biomedcentral.com//47/-2407/7//92

(c) 2007 Lorentzen et al; licensee BioMed Central Ltd.

This is an Open Access article distributed under the terms of the Creative Commons Attribution License (http://creativecommons.org/licenses/by/2.0), which permits unrestricted use, distribution, and reproduction in any medium, provided the original work is properly cited.

\begin{abstract}
Background: It has recently been shown that NDRG2 mRNA is down-regulated or undetectable in several human cancers and cancer cell-lines. Although the function of NDRG2 is unknown, high NDRG2 expression correlates with improved prognosis in high-grade gliomas. The aim of this study has been to examine NDRG2 mRNA expression in colon cancer. By examining affected and normal tissue from individuals with colorectal adenomas and carcinomas, as well as in healthy individuals, we aim to determine whether and at which stages NDRG2 down-regulation occurs during colonic carcinogenesis.
\end{abstract}

Methods: Using quantitative RT-PCR, we have determined the mRNA levels for NDRG2 in lowrisk $(n=15)$ and high-risk adenomas $(n=57)$, colorectal carcinomas $(n=50)$ and corresponding normal tissue, as well as control tissue from healthy individuals $(n=15)$. NDRG2 levels were normalised to $\beta$-actin.

Results: NDRG2 mRNA levels were lower in colorectal carcinomas compared to normal tissue from the control group $(p<0.00 \mathrm{I})$. When comparing adenomas/carcinomas with adjacent normal tissue from the same individual, NDRG2 expression levels were significantly reduced in both highrisk adenoma $(p<0.00 \mathrm{I})$ and in colorectal carcinoma $(\mathrm{p}<0.00 \mathrm{I})$. There was a trend for NDRG2 levels to decrease with increasing Dukes' stage $(p<0.05)$.

Conclusion: Our results demonstrate that expression of NDRG2 is down-regulated at a late stage during colorectal carcinogensis. Future studies are needed to address whether NDRG2 downregulation is a cause or consequence of the progression of colorectal adenomas to carcinoma. 


\section{Background}

N-myc Downstream Regulated Gene 2 (NDRG2) is a member of a recently identified gene family which has been implicated in human nervous system disorders and cancer [1]. Although the four members of this family contain a putative $\alpha / \beta$-hydrolase fold, it is unclear whether or not they have enzymatic activity [2]. NDRG1 was first identified as a gene under negative regulation by $\mathrm{N}$-myc in early mouse development [3]. NDRG2 was identified through sequence homology and is implicated in cell growth, differentiation and neurodegeneration [4-7]. Recently, it has been shown that expression of NDRG2 is transcriptionally repressed by c-Myc [8].

Several studies have suggested that NDRG2 mRNA is down-regulated or undetectable in a number of human cancers and cancer cell-lines [4,9-11]. Semiquantitative RT-PCR was used to demonstrate that NDRG2 expression levels were reduced in squamous cell carcinoma, pancreatic cancer and glioblastoma compared to normal tissue $[4,9,11]$. NDRG2 expression levels in gliomas and meningiomas were significantly attenuated in high-grade compared to low-grade tumors [4,10]. In meningiomas, higher expression of NDRG2 mRNA correlated with clinically less aggressive tumors [10]. Furthermore, NDRG2 was identified as a gene whose expression in high-grade gliomas was positively correlated with survival [12]. Forced NDRG2 overexpression in a human glioblastoma cell-line markedly inhibited cell proliferation [4]. These findings implicate NDRG2 as a possible tumor suppressor gene.

Prompted by the finding that NDRG2 expression correlates inversely with tumor grade in various cancers, we set out to analyse NDRG2 mRNA expression during colorectal carcinogenesis in humans.

\section{Methods}

\section{Subject population}

The KAM cohort (Kolorektal cancer, Arv og Miljø) is based primarily on the screening group of the Norwegian Colorectal Cancer Prevention study (the NORCCAP study, ID number at Clinicaltrials.gov NCT00119912) in the county of Telemark, Norway $[13,14]$. Additionally, a series of colorectal cancer cases were recruited to the KAM cohort from routine clinical work at Telemark Hospital and Ulleval University Hospital in Oslo. A total of 20,780 men and women, age distribution 50-64 years, randomly drawn from the population registries in Oslo (urban) and the county of Telemark (mixed urban and rural) were invited to have a flexible sigmoidoscopy (FS) screening examination with or without $(1: 1)$ an additional faecal occult blood test (FOBT). A total of 777 (4\%) individuals were excluded according to the exclusion criteria [13]. The KAM biobank currently consists of 234 colorectal cancer, 1044 adenoma (229 high-risk, 762 low-risk and 53 hyperplastic polyps) and 400 control specimens. Controls were defined as individuals with normal findings at FS. The KAM study is approved by the Regional Committee for Medical Research Ethics and the Norwegian Data Inspectorate. In the present study we have analyzed carcinomas $(n=50)$, adenomas $(n=72)$ and controls $(n=15)$. Each case was classified according to the degree of malignancy. A sample of control tissue was collected $30 \mathrm{~cm}$ from the anus of patients with adenomas, whereas two samples of control tissue were taken from the surgical specimen from patients with carcinomas: one sample in close proximity (normal adjacent) and one sample as far away from the tumor as possible (normal distant). Control samples were collected from individuals without adenomas or carcinomas. The histology of the adenomas was examined by two histopathologists independently. The degree of dysplasia was determined as either mild/moderate $(n=52)$ or severe $(n=20)$. The two pathologists reached the same conclusion in all cases. Furthermore, adenomas were classified as either low-risk $(n=15)$ or high-risk $(n=57)$. A high-risk adenoma is defined as an adenoma measuring $\geq$ $10 \mathrm{~mm}$ in diameter and/or with villous components and/ or showing severe dysplasia [13]. The vast majority of CRC samples had 75-80\% tumor cells surrounded by stroma, as evaluated by hematoxylin and eosin staining by a pathologist. The distribution of gender and age among controls and cases with colonic carcinoma or adenoma are shown in Table 1.

Table I: Characteristics of cases and healthy persons in this study.

\begin{tabular}{|c|c|c|c|c|}
\hline & \multirow[t]{2}{*}{ Controls } & \multicolumn{3}{|c|}{ Cases } \\
\hline & & Low-risk adenomas & High-risk adenomas' & Carcinomas \\
\hline & $n=15$ & $n=15$ & $n=57$ & $\mathrm{n}=\mathbf{5 0}$ \\
\hline Men & 5 & 12 & 40 & 31 \\
\hline Women & 10 & 3 & 17 & 19 \\
\hline Mean age $^{2}(S D)$ & $57.3(4.9)$ & $56.7(4.4)$ & $56.4(3.8)$ & $71.8(10.5)$ \\
\hline
\end{tabular}

'A high-risk adenoma is defined as an adenoma measuring $\geq 10 \mathrm{~mm}$ in diameter and/or with villous components and/or showing severe dysplasia.

${ }^{2}$ There are significant differences in age among the four groups of healthy and affected individuals at $95 \%$ confidence level (Kruskal-Wallis test). 


\section{Cancer Profiling Array (CPA)}

The Cancer Profiling Array II (Clontech) was hybridised with 50 ng of radioactively labelled NDRG2 probe according to the manufacturer's instructions. The $460 \mathrm{bp}$ NDRG2 probe was generated by PCR using the primers 5'CTCACTCTGTGGAGACACCAT3' and 5'GGGTGATATCACCTCCACGCT3'. The hybridised array was exposed to a phosphorimaging screen for 24 hours and the intensity of each spot was quantified using ImageQuant (Molecular Dynamics). The CPA consists of paired cDNA samples generated from the total RNA of normal and tumor tissue. Because the array is normalised for several housekeeping genes, quantification of the hybridisation signal provides an estimate of relative transcript abundance.

\section{RT-PCR}

Total RNA was purified from tissue as recommended by the manufacturers using an e.z.n.a. Gel Extraction kit (Omega Biotek). The tissue had been snap-frozen in liquid $\mathrm{N}_{2}$ and stored at $-80^{\circ} \mathrm{C}$ before RNA purification. RNA purification included a DNAse treatment. The cDNA synthesis was performed on approximately $200 \mathrm{ng}$ RNA per $10 \mu \mathrm{l}$ using the High Capacity cDNA Reverse Transcription kit (Applied Biosystems, Nærum, Denmark). Quantitative RT-PCR was performed on an ABI7500 sequence detection system (Applied Biosystems) in Universal Mastermix (Applied Biosystems) using $220 \mathrm{nM}$ probe and 700 nM primers for NDRG2. NDRG2 primers were NDRG2F: 5'CGATCCTTACCTACCACGATGTG3' and NDRG2R: 5'GCATGTCCTCGAACTGAAACAGT3' and the probe was 5'FAM-CTCAACTATAAATCTTGCTTCC-MGB-NFQ-3'.

Primers were designed using Primer Express v3.0 Software and obtained from DNA Technology A/S. Primers were designed within different exons and with a probe covering the exon-exon border to prevent amplification of genomic DNA. The probe recognises all splice forms of NDRG2. $\beta$ actin primers and probe were obtained from Applied Biosystems. In a validation experiment using a control sample, a dilution series was produced and assayed for NDRG2 and $\beta$-actin expression as described in the comparative $C_{t}$ method [15]. When $C_{t}$ values were plotted against log dilution it was shown that the assays are quantitative over a range of 128-fold dilution for both NDRG2 and $\beta$-actin and that the PCR reactions have similar efficiencies provided that a threshold of 0.2 is used for $\beta$ actin, while the threshold was 0.07 for NDRG2. The threshold is a fixed fluorescence signal above the baseline. The $\mathrm{C}_{\mathrm{t}}$ value of a sample is determined as the fractional cycle number when the sample's fluorescence signal exceeds the threshold. The threshold is thus assay-specific, determined in the validation experiment and depends on the background of the individual assay.
NDRG2 and $\beta$-actin mRNAs were quantified separately in triplicates. The average standard deviations on triplicates were $15 \%$ and $11 \%$ for NDRG2 and $\beta$-actin respectively. The standard deviation on repeated measurements of the same sample (internal control) in separate experiments was $16 \%$ for NDRG2, indicating the day-to-day variation of the assay. Negative controls (where the RNA was not converted into cDNA) and positive controls were included in all sets. Two independent PCR reactions of 28 samples (5\%) yielded a correlation coefficient of 0.95 , indicating a high reproducibility of the assay.

\section{Statistical analysis}

GraphPad Prism 4 was used for the statistic calculations. The data were not adjusted for sex since the incidence ratio of colorectal cancer between genders (Male: 1128 and female: 1217 new cases in 2004) is 1:1 in Norway [16]. $P$ values $<0.05$ were considered significant for all statistical tests.

\section{Results \\ Expression of NDRG2 mRNA in colonic adenomas and carcinomas}

Preliminary experiments using a Cancer Profiling Array indicated that expression of NDRG2 mRNA was reduced in 9 out of 10 colonic tumors (Table 2). Using a two-tailed paired t-test, the decrease in NDRG2 expression in tumors as compared to the corresponding normal tissues was found to be statistically significant $(\mathrm{p}<0.01)$. Prompted by this finding, we decided to analyse NDRG2 mRNA expression in normal and neoplastic tissue in a larger number of patients to confirm and extend our results.

Using real-time RT-PCR we have measured the levels of NDRG2 mRNA in colonic tissue from healthy individuals and from individuals with colorectal adenomas or carcinoma (Table 1). It was observed that the expression of NDRG2 mRNA in colorectal tissue is relatively low compared to the expression of $\beta$-actin, which was used for normalisation (Figure 1). Upon examination of the mean values in affected tissue (low- and high-risk adenomas and carcinoma), a trend towards a decreased NDRG2 expression with increasing tumor grade was observed $(\mathrm{p}<$ 0.001 ) (Figure 1).

Analysis of the data using a one-way ANOVA with Tukey's post test did not show any significant difference in NDRG2 mRNA level between the control group and either normal or affected tissue from individuals with adenoma (low- and high-risk). This was also the case when comparing normal tissue from individuals with colorectal cancer to the control group. However, when comparing affected tissue from individuals with colorectal cancer to corresponding tissue from a healthy control, a statistically sig- 
Table 2: Expression analysis of NDRG2 in colon cancer using a Cancer Profiling Array.

\begin{tabular}{|c|c|c|c|c|c|}
\hline Sample & Signal intensity & Tumor/normal & TNM staging & Age & Gender \\
\hline Tumor/normal & $18370 / 600 \mid 5$ & 0.31 & II; T4NOMO & 67 & Female \\
\hline Tumor/normal & $3|402 / 3543|$ & 0.89 & I; TINOMO & 58 & Female \\
\hline Tumor/normal & $57|25 / 96| 2 \mid$ & 0.59 & IV; T4NOMO & 43 & Female \\
\hline Tumor/normal & $20382 / 23650$ & 0.86 & IIIB; T3NIM0 & 69 & Female \\
\hline Tumor/normal & $28165 / 59167$ & 0.48 & IIIB; T3NIMO & 35 & Female \\
\hline Tumor/normal & $22193 / 12912$ & 1.72 & IIIA; T4N0M0 & 58 & Male \\
\hline Tumor/normal & $18569 / 28122$ & 0.66 & IIIB; T4NIM0 & 63 & Male \\
\hline Tumor/normal & $9863 / 289 \mid 4$ & 0.34 & IIA; T2NOMO & 73 & Female \\
\hline Tumor/normal & $21780 / 34774$ & 0.63 & IIIB; T4NOM? & 65 & Female \\
\hline Tumor/normal & $22429 / 45939$ & 0.49 & IIIA; T3NIM0 & 65 & Female \\
\hline
\end{tabular}

Expression of NDRG2 mRNA was determined by hybridisation of a Cancer Profiling Array with a NDRG2 probe. Quantification of the hybridisation signal for the paired samples revealed that NDRG2 expression was reduced in 9 out of 10 colon tumor samples compared to the corresponding normal sample. Using a two-tailed paired t-test, the decrease in NDRG2 expression in tumors compared to normal samples was found to be statistically significant $(p<0.0 I)$. The tumors were all diagnosed as adenocarcinoma aside from the Stage I tumor which was a tubulovillous adenoma. The TNM staging system describes the extent of the primary tumor $(\mathrm{T})$, the absence/presence of metastasis to nearby lymph nodes $(\mathrm{N})$ and the absence/presence of distant metastases (M).

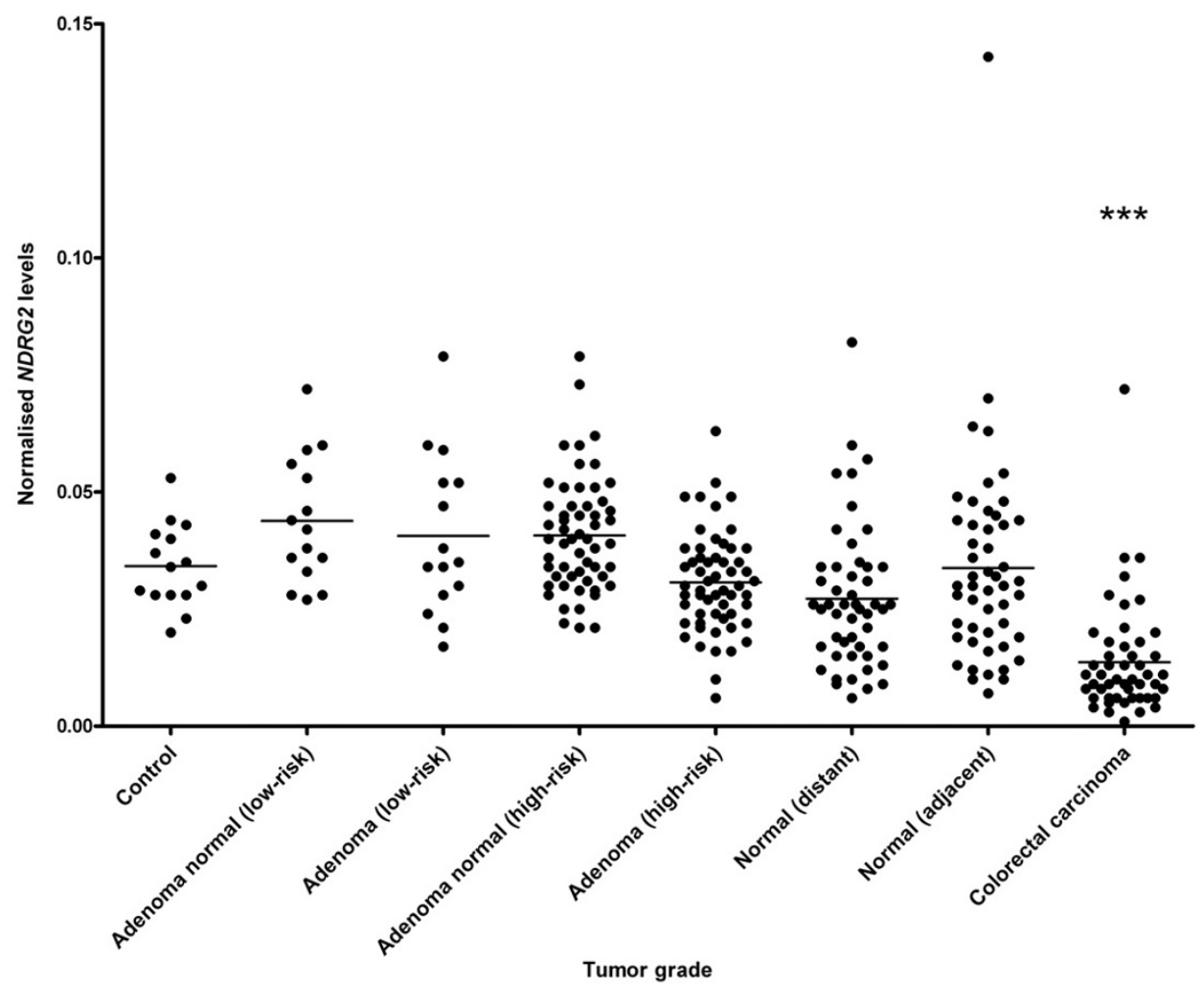

Figure I

NDRG2 mRNA levels are down-regulated during colorectal cancer carcinogenesis. mRNA expression of NDRG2 determined by real-time RT-PCR and normalised to $\beta$-actin in healthy individuals (Control), normal and affected tissue from the same individual with adenomas (low- or high-risk) and colorectal carcinoma. Normal (adjacent): normal sample close to the carcinoma, Normal (distant): normal sample far from the carcinoma. Each dot represents mean values of triplicate determinations. *** $\mathrm{p}<0.001$ compared to the control group using one-way ANOVA with a Tukey's post test. A trend of decreased NDRG2 expression with increasing tumor grade was observed in affected tissue $(p<0.00 \mathrm{I})$. 
nificant difference in the level of NDRG2 mRNA was observed $(\mathrm{p}<0.001)$ (Table 3$)$.

Further analysis of the different groups of affected tissue using a paired two-tailed t-test showed that the level of NDRG2 in individuals with low-risk adenoma did not show any significant difference between normal and neoplastic tissue. However, a comparison of normal and high-risk adenoma from the same individual showed a highly statistically significant reduction $(\mathrm{p}<0.001)$ in NDRG2 level. Finally, comparing the level of NDRG2 mRNA in normal tissue far (normal distant) and close (normal adjacent) to that of the tumor in the surgical specimens of CRC patients showed a statistically significant difference $(\mathrm{p}<0.001)$ in both cases (Table 3$)$.

Cases of adenomas can also be classified according to the diagnosed degree of dysplasia (mild/moderate or severe) (Table 4). When comparing affected tissue with normal tissue from the same individual, we found a statistically significant difference in NDRG2 expression for individuals with mild/moderate dysplasia $(\mathrm{p}<0.001)$ (Table 4$)$.

\section{Analysis of expression levels in carcinomas according to Dukes' staging}

Colorectal cancer can be staged according to different systems. In this study all samples of colorectal carcinoma (CRC) were classified as Dukes' stage A-C where $\mathrm{C}$ is the most advanced and metastatic stage. Figure 2 presents data showing that the level of NDRG2 mRNA decreases with increasing Dukes' stage. By calculating linear regression on the data, the result was a statistically significant linear trend $(\mathrm{p}<0.05)$ for decreasing NDRG2 levels with increasing tumor stage.

\section{Expression patterns of NDRG2 between genders in colorectal cancer}

The incidence of new cases of colorectal cancer in Norway is in the ratio 1:1 between the two genders [16]. Dividing all data collected in this study into groups of males and females showed a general lower level of NDRG2 expres- sion in females with colorectal carcinoma (both normal and cancer tissue) (Figure 3). However, this difference was not statistically significant using a one-way ANOVA with Tukey's post test.

\section{Discussion}

In the present study we demonstrated that NDRG2 mRNA expression levels were lower in colonic tumors than in normal colon tissue from the same individual. This was observed using two distinct subject populations, one of which was a Norwegian cohort, the other a group of affected individuals based on a commercially available product. The difference in mRNA level is likely to be reflected at the level of NDRG2 protein, since NDRG2 mRNA levels have previously been shown to correlate well with protein levels [8].

In the Norwegian cohort, NDRG2 mRNA levels were statistically significantly reduced in colorectal carcinoma when compared to the healthy controls. In order to examine whether the risk of carcinoma is affected by changes in the microenvironment, expression levels of NDRG2 in the lesion were compared to normal adjacent tissue as well as to normal tissue distant from the tumor. NDRG2 mRNA was statistically significantly reduced in tumor compared to either normal tissue sample. No difference was observed between the adjacent and distant samples, suggesting that changes in NDRG2 expression in the carcinoma are not attributable to the microenvironment.

Recent studies have demonstrated that colorectal cancer is a heterogenous disease with distinct molecular components. Distinct genetic or epigenetic alterations have been identified which correlate with the location of the tumors [17]. Although it was not investigated in this study, it could be interesting to compare NDRG2 expression in tumors located in either the proximal or distal colon.

There was a tendency for decreasing NDRG2 mRNA levels with increasing tumor stage according to Dukes' staging of the CRC samples, and this trend was found to be signifi-

Table 3: Mean values of normalised levels of NDRG2 mRNA in normal and affected colonic tissues.

\begin{tabular}{|c|c|c|c|c|c|}
\hline & $\begin{array}{l}\text { mRNA level in normal } \\
\text { tissue Mean (SD) }\end{array}$ & $\mathbf{p}^{\mathbf{a}}$ & $\begin{array}{c}\text { mRNA level in } \\
\text { adenomas/carcinomas Mean (SD) }\end{array}$ & $\mathbf{p}^{\mathbf{a}}$ & $\mathbf{p}^{\mathbf{b}}$ \\
\hline Control & $\mathbf{0 . 0 3 4}(0.009)$ & & $0.0407(0.017)$ & & \\
\hline Low-risk Adenoma & $0.044(0.014)$ & NS & $0.0307(0.011)$ & NS & NS \\
\hline High-risk Adenoma & $0.041(0.012)$ & NS & & NS & $<0.001$ \\
\hline Carcinoma Normal (distant) & $0.027(0.015)$ & NS & & $<0.001$ & $<0.00 \mathrm{I}^{\mathrm{c}}$ \\
\hline Carcinoma Normal (adjacent) & $0.034(0.021)$ & NS & & & $<0.00 \mathrm{I}^{\mathrm{d}}$ \\
\hline
\end{tabular}

NS = not significant.

${ }^{a} \mathrm{p}$ value when expression levels were compared to the control group of healthy individuals using one-way ANOVA with a Tukey's post test.

${ }^{b} \mathrm{p}$ value for comparison of mRNA expression levels in normal and tumor samples from the same individual using a paired two-tailed T-test.

${ }^{c} \mathrm{p}$ value when normal (distant) and corresponding tumor sample were compared.

${ }^{d} \mathrm{p}$ value when normal (adjacent) and corresponding tumor sample were compared. 
Table 4: Mean values of normalised levels of NDRG2 mRNA in adenomas'.

\begin{tabular}{|c|c|c|c|c|c|}
\hline & $\begin{array}{c}\text { mRNA level in normal } \\
\text { tissue Mean (SD) }\end{array}$ & $\mathbf{p}^{\mathbf{a}}$ & $\begin{array}{c}\text { mRNA level in } \\
\text { adenomas Mean (SD) }\end{array}$ & $\mathbf{p}^{\mathbf{a}}$ & $\mathbf{p}^{\mathbf{b}}$ \\
\hline Mild/moderate Dysplasia & $0.042(0.012)$ & NS & $0.032(0.014)$ & NS & $<0.001$ \\
\hline Severe Dysplasia & $0.040(0.014)$ & NS & $0.034(0.011)$ & NS & NS \\
\hline
\end{tabular}

NS = not significant.

ICases of adenomas were divided into mild/moderate $(n=52)$ or severe $(n=20)$ according to the diagnosed degree of dysplasia.

${ }^{a} \mathrm{P}$ value when expression levels were compared to the control group of healthy individuals using one-way ANOVA with a Tukey's post test.

${ }^{\mathrm{b}} \mathrm{p}$ value for comparison of mRNA expression levels in normal and tumor samples from the same individual using a paired two-tailed T-test.

cant using linear regression $(\mathrm{p}<0.05)$. Our results are in agreement with that observed for other cancer types where NDRG2 expression is reduced in high-grade compared to low-grade tumors $[4,10]$. This trend indicates either that the loss of NDRG2 promotes tumor progression or that NDRG2 is inactivated by factor(s) present at advanced tumor stages. NDRG2 has previously been shown to be negatively regulated by the c-Myc oncoprotein [8] and it is possible that elevated levels of c-Myc would result in

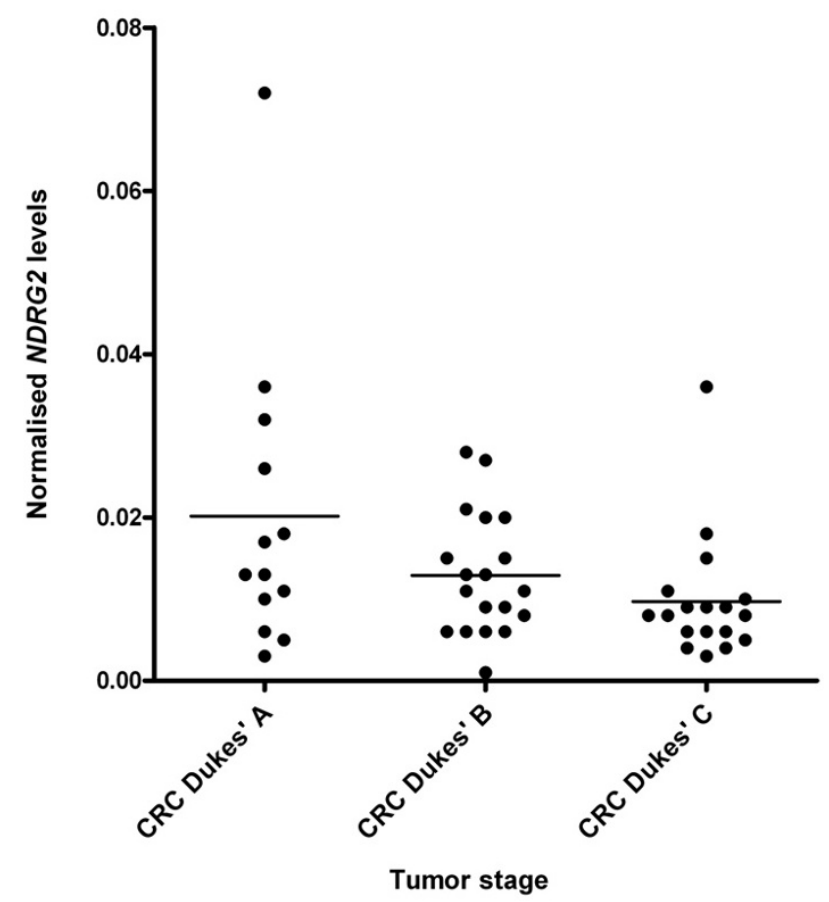

\section{Figure 2}

\section{NDRG2 mRNA levels decrease with increasing}

Dukes' stage. Samples with colorectal cancer (CRC) staged after the Dukes' staging system with I 3 samples categorised as Dukes' A, 19 samples as Dukes' B and 18 samples as Dukes' $C$. The graph shows the normalised level of NDRG2 mRNA in samples from the different Dukes' stages. Calculating linear regression using each column of data resulted in a statistically significant linear trend $(p<0.05)$ for a decrease in NDRG2 level with increasing Dukes' stage. reduced expression of NDRG2. Thus, it could be interesting to elucidate whether or not an increased level of c$\mathrm{Myc}$, which is a frequent event in colorectal cancer [18], correlates with a decreased level of NDRG2. Measurement of c-Myc levels was not included in these studies. However, we have investigated a subset of the CRC samples ( $\mathrm{n}$ $=54$ ) from the KAM study for $\beta$-catenin expression by immunohistochemistry. All of the tested CRC samples are positive for cytoplasmic $\beta$-catenin and $72 \%$ are $\beta$-catenin positive in all nuclei (data not shown). The remaining samples contain nuclear $\beta$-catenin in occasional nuclei. This suggests that c-Myc levels are likely to be elevated since c-Myc is known to be positively regulated by nuclear $\beta$-catenin [19].

In order to determine the stage at which NDRG2 expression is down-regulated in the adenoma-carcinoma sequence we also examined normal and affected tissue

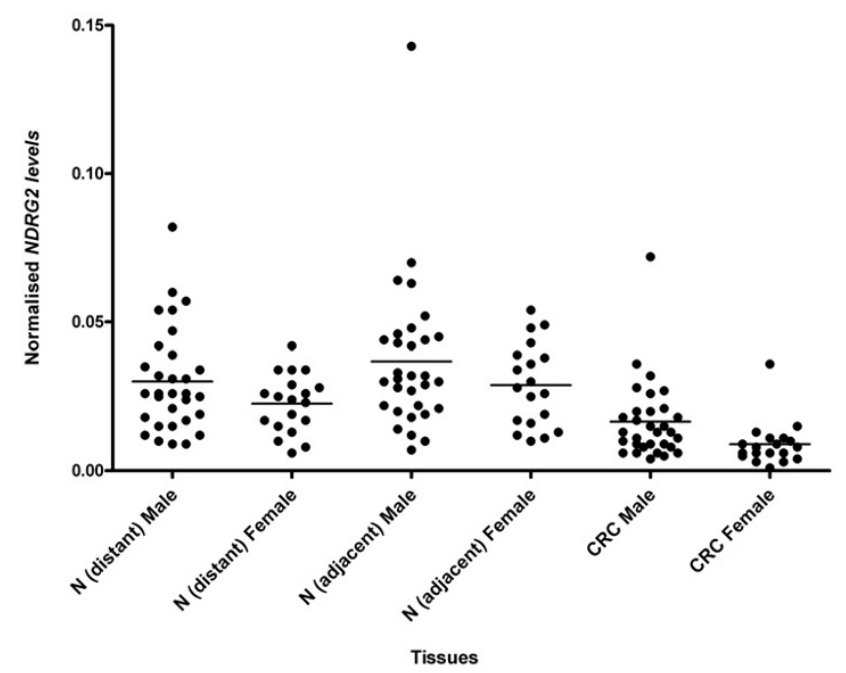

Figure 3

NDRG2mRNA levels are lower in females compared to males. Expression levels of NDRG2 mRNA in samples with colorectal carcinomas (CRC) divided according to gender. A general lower level of expression was observed in females. $\mathrm{N}$ (adjacent): normal sample close to the tumor, $\mathrm{N}$ (distant): normal sample far from the tumor. 
from low- and high-risk adenomas. When comparing affected tissue with normal tissue from the same individual, we found a statistically significant difference for individuals with high-risk adenomas. However, when compared to the control group of healthy individuals, only the affected tissue from individuals with colorectal carcinoma shows a statistically significant reduction in NDRG2 mRNA levels. Our results suggest that down-regulation of NDRG2 expression occurs during the progression from adenoma to carcinoma.

Whether down-regulation of NDRG2 in colorectal carcinoma is a cause or a consequence of malignant progression is at present unclear. Although the structure of NDRG2 resembles that of a hydrolase [2], its ability to function as an enzyme is presently unknown. It has recently been shown that overexpression of NDRG2 in a glioblastoma cell-line inhibits cell proliferation [4] and that NDRG2 expression correlates positively with survival in high-grade glioma [12]. NDRG2 levels are also reduced in several cancer types and cell-lines [4,9-11]. Thus, NDRG2 may have a general function in diverse tissues as a tumor suppressor gene. Future studies will be needed to examine whether increased NDRG2 levels in colorectal carcinoma correlate with improved prognosis.

\section{Conclusion}

In conclusion, NDRG2 mRNA levels were decreased in both high-risk colorectal adenoma and in colorectal carcinoma compared to corresponding normal colonic mucosa from the same individual. Furthermore, NDRG2 expression was reduced in colorectal carcinoma compared to normal tissue from healthy individuals. Our results suggest that NDRG2 down-regulation correlates with the progression of dysplastic tissue to carcinoma. Future studies are needed to address whether NDRG2 down-regulation is a cause or consequence of colorectalcarcinogenesis.

\section{Competing interests}

The author(s) declare that they have no competing interests.

\section{Authors' contributions}

LKV and CM conceived the idea of the study and designed the primers and probes. EHK designed and administered the KAM study and collected the samples. LKV, MS and CFS extracted the RNA and carried out the cDNA synthesis. SG organised the cDNA bank used in this study. GH together with KMT were responsible for designing and administering the NORCCAP clinical trial. IMBL was responsible for the pathology of the cancer cases. TI contributed with scientific input to the study. AL validated the primers and probes, carried out the RT-PCR and performed most of the statistical calculations. RL carried out the Cancer Profiling Array analysis. CM and AL drafted the manuscript. LKV helped writing the manuscript. All authors contributed to interpretation and discussion of the results and read and approved the final version.

\section{Acknowledgements}

This work was supported by The Norwegian Cancer Society (Grant numbers 51024/00 I and EOI-085I00I), Telemark University College (Grant number 22069), the Norwegian Colorectal Cancer Prevention (NORCCAP) study, grants from the Norwegian Cancer Society and the Department of Health and Social Affairs with the aid of EXTRA funds from the Norwegian Foundation for Health and Rehabilitation (200I/2/0 I I0), Eastern Norway Regional Health Authority, the Danish Medical Research Council, Novo Nordisk Foundation and the Danish Cancer Society (DP05II7).

We thank Dr. Gunter Bock and Dr. Egil Johnson for collecting tumor tissues and Dr. Steinar Aase for contributing to the pathology of the cancer cases.

We thank Christel A. Halberg for her excellent technical assistance.

\section{References}

I. Mitchelmore C, Buchmann-Moller S, Jensen NA: The NDRG gene family and human nervous system disorders. Cognitive Sciences 2007, I:I37-151 [https://www.novapublishers.com/catalog/ product info.php?products id $=4758$.

2. Shaw E, Mccue LA, Lawrence CE, Dordick JS: Identification of a novel class in the alpha/beta hydrolase fold superfamily: The N-myc differentiation-related proteins. Proteins 2002, 47:163-168.

3. Shimono A, Okuda $\mathrm{T}$, Kondoh $\mathrm{H}$ : $\mathbf{N}$-myc-dependent repression of Ndrl, a gene identified by direct subtraction of whole mouse embryo cDNAs between wild type and N-myc mutant. Mech Dev 1999, 83:39-52

4. Deng YC, Yao LB, Chau L, Ng SSM, Peng Y, Liu XP, Au WS, Wang JC, Li FY, Ji SP, Han H, Nie XY, Li Q, Kung HF, Leung SY, Lin MCM: Nmyc downstream-regulated gene 2 (NDRG2) inhibits glioblastoma cell proliferation. Int J Cancer 2003, 106:342-347.

5. Qu XH, Zhai Y, Wei HD, Zhang CG, Xing GC, Yu YT, He FC: Characterization and expression of three novel differentiationrelated genes belong to the human NDRG gene family. Mol Cell Biochem 2002, 229:35-44.

6. Mitchelmore C, Buchmann-Moller S, Rask L, West MJ, Troncoso JC, Jensen NA: NDRG2: a novel Alzheimer's disease associated protein. Neurobiol Dis 2004, 16:48-58.

7. Choi SC, Kim KD, Kim JT, Kim JW, Yoon DY, Choe YK, Chang YS, Paik SG, Lim JS: Expression and regulation of NDRG2 (N-myc downstream regulated gene 2 ) during the differentiation of dendritic cells. FEBS Lett 2003, 553:4I3-4I8.

8. Zhang J, Li F, Liu X, Shen L, Liu J, Su J, Zhang W, Deng Y, Wang L, Liu $\mathrm{N}$, Han W, Zhang J, Ji S, Yang A, Han H, Yao L: The repression of human differentiation-related gene NDRG2 expression by Myc via Miz-I-dependent interaction with the NDRG2 core promoter. J Biol Chem 2006, 281:39159-39168.

9. Hummerich L, Muller R, Hess J, Kokocinski F, Hahn M, Furstenberger $G$, Mauch C, Lichter P, Angel P: Identification of novel tumourassociated genes differentially expressed in the process of squamous cell cancer development. Oncogene 2006, 25: III-12I.

10. Lusis EA, Watson MA, Chicoine MR, Lyman M, Roerig P, Reifenberger $G$, Gutmann DH, Perry A: Integrative genomic analysis identifies NDRG2 as a candidate tumor suppressor gene frequently inactivated in clinically aggressive meningioma. Cancer Research 2005, 65:7121-7I 26.

11. Hu XL, Liu XP, Lin SX, Deng YC, Liu N, Li X, Yao LB: NDRG2 expression and mutation in human liver and pancreatic cancers. World J Gastroenterol 2004, 10:3518-352I.

12. Phillips HS, Kharbanda S, Chen R, Forrest WF, Soriano RH, Wu TD, Misra A, Nigro JM, Colman H, Soroceanu L, Williams PM, Modrusan Z, Feuerstein BG, Aldape K: Molecular subclasses of high-grade glioma predict prognosis, delineate a pattern of disease pro- 
gression, and resemble stages in neurogenesis. Cancer Cell 2006, 9:157- 173.

13. Gondal G, Grotmol T, Hofstad B, Bretthauer M, Eide TJ, Hoff G: The Norwegian Colorectal Cancer Prevention (NORCCAP) screening study: baseline findings and implementations for clinical work-up in age groups $50-64$ years. Scand J Gastroenterol 2003, 38:635-642.

14. Clinical Trials 2007 [http://clinicaltrials.gov].

15. Johnson MR, Wang K, Smith JB, Heslin MJ, Diasio RB: Quantitation of dihydropyrimidine dehydrogenase expression by realtime reverse transcription polymerase chain reaction. Anal Biochem 2000, 278: $175-184$

16. Norway TCR: Cancer in Norway 20042006 [http://www.cancerregis try.no]. Oslo, Infoprint

17. Sugai T, Habano W, Jiao YF, Tsukahara M, Takeda Y, Otsuka K, Nakamura S: Analysis of molecular alterations in left- and rightsided colorectal carcinomas reveals distinct pathways of carcinogenesis: proposal for new molecular profile of colorectal carcinomas. J Mol Diagn 2006, 8:193-20I.

18. Nesbit CE, Tersak JM, Prochownik EV: MYC oncogenes and human neoplastic disease. Oncogene 1999, 18:3004-3016.

19. Behrens J: The role of the Wnt signalling pathway in colorectal tumorigenesis. Biochem Soc Trans 2005, 33:672-675.

\section{Pre-publication history}

The pre-publication history for this paper can be accessed here:

http://www.biomedcentral.com/1471-2407/7/192/pre

pub

Publish with Biomed Central and every scientist can read your work free of charge

"BioMed Central will be the most significant development for disseminating the results of biomedical research in our lifetime. "

Sir Paul Nurse, Cancer Research UK

Your research papers will be:

- available free of charge to the entire biomedical community

- peer reviewed and published immediately upon acceptance

- cited in PubMed and archived on PubMed Central

- yours - you keep the copyright

Submit your manuscript here:

http://www.biomedcentral.com/info/publishing_adv.asp 